\title{
INTERRELATIONSHIP OF PREFRONTAL BRAIN-DERIVED NEUROTROPHIC FACTOR AND NEUROENDOCRINE SYSTEM DURING CHRONIC RESTRAINT STRESS
}

\author{
Nataša Popović, Vesna Stojiljković, Snežana Pejić, Ana Todorović, \\ Ivan Pavlović, Snežana B. Pajović, Ljubica Gavrilović* \\ Laboratory of Molecular Biology and Endocrinology, \\ Institute of Nuclear Sciences Vinča, University of Belgrade, Belgrade, Serbia
}

\begin{abstract}
The hypothalamic-pituitary-adrenal (HPA) axis plays an important role in the adaptation of the organism to stress. Because of a key role of neuroendocrine system in response to a stressful situation, as well as a significant impact of stress on neuronal plasticity, in this work we investigated how chronic restraint stress (CRS: 2 hours $\times 14$ days) affected the protein levels of BDNF in the prefrontal cortex (PFC), as well as the concentration of adrenocorticotropic hormone (ACTH) and corticosterone (CORT) in the plasma. In addition, the aim of this study was to determine a possible correlation between levels of BDNF in the PFC and plasma CORT levels of animals exposed to CRS. We found that CRS increases levels of prefrontal BDNF protein by $25 \%$ and levels of CORT by $280 \%$, but decreases levels of ACTH by 18\%. Also, we recorded a low, but significant positive correlation between prefrontal $B D N F$ levels and concentrations of CORT in the plasma of chronically stressed rats. Our data confirm that prefrontal $B D N F$ might be an important regulator involved in the adaptive strategy of the HPA axis to maintain adequate reactivity in stress conditions provoked by CRS.
\end{abstract}

Keywords: Adrenocorticotropic hormone, brain-derived neurotrophic factor, chronic restraint stress, corticosterone

\section{INTRODUCTION}

The hypothalamic-pituitary-adrenal (HPA) axis is very significant in the adaptation of the organism to stress [1]. Numerous studies have confirmed that the HPA axis plays an important role in the pathophysiology of stress-related psychiatric diseases [2]. It is known that the most important neuroendocrine abnormality in depression is HPA axis hyperactivity [3]. In addition, the prefrontal cortex (PFC) is an important brain region in the pathology of depression [4]. The literature data have shown that the medial PFC lesion increases depression-like behavior [5], and the HPA axis is disrupted due to this lesion as well [6]. In addition, the research of the immunoneurobiological interactions is also important for the understanding of etiopathogenesis of mood disorders. For example, the levels of immune biomarkers are a significant predictor of depressive and bipolar disorder [7]. In our previous studies, we confirmed that chronic restraint stress (CRS) provokes depressive-like behaviors in rats [8] and that this stress has a significant impact on hippocampal neuronal plasticity [9]. Phillips [10] showed that chronic stress lowers the brain-derived neurotrophic factor (BDNF). In addition, Dunham et al. [11] observed that BDNF mRNA and protein levels are suppressed in the postmortem brains of depressed patients. Also, Numakawa [12] have suggested that the downregulation of expression and function of BDNF is associated with the onset of depression. However, very little is known about the interrelationship of prefrontal BDNF levels and HPA axis activity during CRS. Because of a key role of neuroendocrine system in response to a stressful situation, as well as significant impact of stress on neuronal plasticity, in this work we investigated how chronic restraint stress (CRS: 2 hours $\times 14$ days) affected the protein levels of BDNF in the prefrontal cortex (PFC), as well as concentration of adrenocorticotropic hormone (ACTH) and corticosterone (CORT) in the plasma. An additional aim of the study was to determine a possible correlation between BDNF expression in the PFC and plasma CORT levels of animals exposed to CRS. Detecting the degree of correlation between HPA axis activity and neuronal plasticity in the PFC in stress conditions is important for indicating the possible causative relationship between stress-activated systems.

\section{METHODS \\ 2.1. Animals and stress models}

Wistar male rats (11-week-old) were kept under standard laboratory conditions with water and food $a d$

*gljubica@vin.bg.ac.rs 
libitum, three to four per cage [13]. In accordance with our previous protocol [14] animals were divided into two groups: the CONTROL group $(n=10)$ was not exposed to any treatment and the CRS group $(n=10)$ consisted of animals exposed to the treatment of chronic restraint stress. Animals in CRS groups were exposed to $2 \mathrm{~h}$ of restraint stress every day, for a period of 14 days, which is in accordance with the protocol of Popović et al. [14]. Animals were sacrificed under nostress conditions by rapid decapitation. The prefrontal cortices were rapidly dissected, frozen in liquid nitrogen and stored at $-70^{\circ} \mathrm{C}$ until analyzed.

2.2. $R N A$ isolation, $c D N A$ synthesis and real-time $R T-P C R$

Methods of RNA isolation and cDNA synthesis have been described previously by Gavrilović et al. [13]. BDNF mRNA levels were quantified by quantitative real-time RT-PCR. TaqMan PCR assays were carried out using Assay-on-Demand Gene Expression Products (Applied Biosystems, USA) for BDNF (Rno1484924_m1) and for cyclophilin A - endogenous control (Rnoo690933_m1). The relative expression of the target gene was normalized to cyclophilin A and expressed in relation to the calibrator, i.e. the control sample as previously described by Gavrilović et al. [13].

\subsection{Western blot analysis}

BDNF protein was assayed by Western blot analysis as described previously by Gavrilović et al. [13]. Antibodies used for quantification of specific proteins were as follows: for BDNF (ab6201, Abcam, USA) and for $\beta$-actin (ab8227, Abcam, USA). After washing, the membranes were incubated in the secondary antimouse and anti-rabbit (dilution 1:5000, Amersham ECL $^{\mathrm{TM}}$ Western Blotting Analysis System, UK) antibodies conjugated to horseradish peroxidase. The result was expressed in arbitrary units normalized in relation to $\beta$ actin, which is in accordance with the protocol of Gavrilović et al. [13].

\subsection{ACTH and CORT measurements}

Plasma ACTH was determined by a chemiluminescent method using IMMULITE automatic analyzer (Diagnostic Products Corporation, Los Angeles, CA, USA) and the values were expressed as pg $\mathrm{ACTH} / \mathrm{ml}$ plasma. The CORT level was determined by using the OCTEIA Corticosterone EIA kit according to the manufacturer's instructions (Immunodiagnostic Systems Inc.). The concentration of CORT $(\mathrm{ng} / \mathrm{ml})$ was determined using a standard curve.

\subsection{Data analysis}

The data are presented as means \pm S.E.M. Differences of gene expression (mRNA and protein levels) of BDNF in the PFC, as well as plasma concentration of ACTH and CORT between control and CRS animals were analyzed by the t-test. Statistical significance was accepted at $\mathrm{p}<0.05$. Correlations of BDNF levels and CORT levels were analyzed by the Pearson test, using the Sigma Plot v10.o (with SigmaStat integration).

\section{RESULTS}

\subsection{Changes in plasma concentrations of ACTH and CORT}

Chronic restraint stress decreased plasma concentrations of ACTH by $18 \%$ ( $<<0.05$, t-test, see Figure 1a) and increased CORT concentration by $280 \%$ ( $\mathrm{p}<0.01$, t-test, see Figure 1b), compared with control animals.

a)

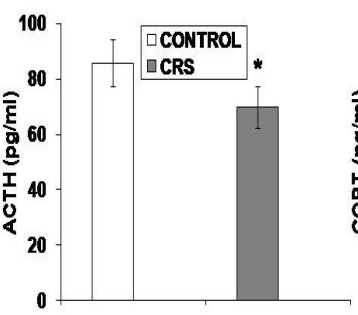

Figure 1. Effects of chronic restraint stress (CRS) on the concentration of adrenocorticotropic hormone (ACTH) [a] and corticosterone (CORT) [b] in the plasma. The values are means \pm S.E.M. of 10 rats. Statistical significance: ${ }^{*} \mathrm{p}<0.05$,

${ }^{* *} \mathrm{p}<0.01$ animals exposed to chronic restraint stress $v s$. control animals (t-test).

\subsection{Changes in the BDNF $m R N A$ levels and BDNF} protein levels in the prefrontal cortex

The animals exposed to CRS showed decreased levels of BDNF mRNA by $50 \%$ ( $\mathrm{p}<0.01$, t-test, see Figure 2a) and increased levels of BDNF protein by $25 \%(\mathrm{p}<0.05$, t-test, see Figure $2 \mathrm{~b})$ in the prefrontal cortex, compared with control animals.

a)

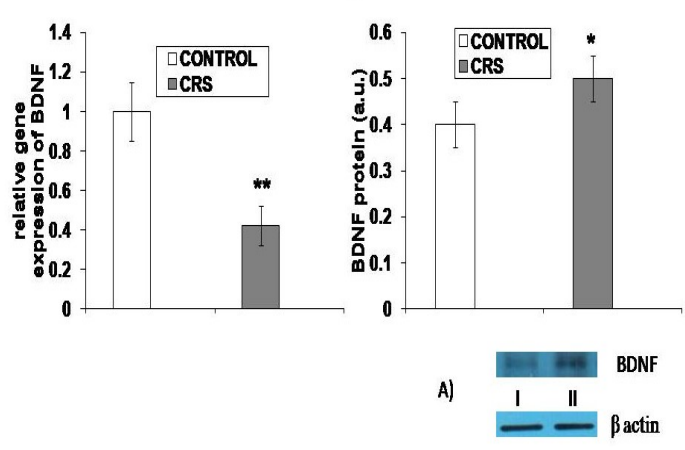

Figure 2. Effects of chronic restraint stress (CRS) on brainderived neurotrophic factor (BDNF) mRNA levels [a] and protein levels $[\mathrm{b}]$ in the prefrontal cortex. The values are means \pm S.E.M. of 10 rats. Statistical significance: ${ }^{*} \mathrm{p}<0.05$,

${ }^{* *} \mathrm{p}<0.01$ animals exposed to chronic restraint stress $v s$. control animals (t-test). Levels of mRNA were expressed as fold change relative to the calibrator and normalized to cyclophilin A and protein levels were expressed in arbitrary units normalized in relation to $\beta$ actin. (A) Distribution of $\mathrm{BDNF}$ and $B$ actin proteins in the prefrontal cortex of control animals [I] and animals exposed to CRS [II]. 
A significant positive correlation was found between the levels of BDNF in the prefrontal cortex and plasma concentration of CORT (Pearson $\mathrm{R}=0.678$; $\mathrm{p}<0.05$, see Figure 3) of animals exposed to CRS.

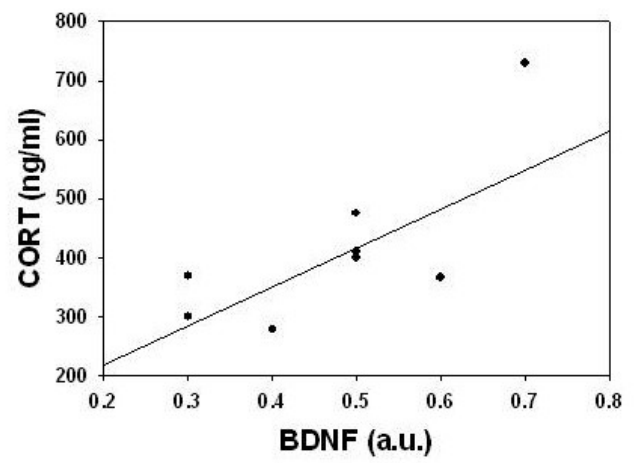

Figure 3. The correlations between BDNF levels in the prefrontal cortex and concentration of corticosterone (CORT) in the plasma (Pearson).

\section{Discussion}

In the present study, we have found that the animals exposed to CRS showed decreased concentrations of ACTH and increased CORT concentration in the plasma. Numerous studies have confirmed that the adaptive mechanism of the HPA axis could be explained by the involvement of extrahypothalamic pathways in CORT control [3], particularly of splanchnic sympathetic innervation [15], which is under the control of hypothalamic paraventricular nucleus (PVN) neurons [16]. Also, arginine-vasopressin (AVP) originating from hypothalamic magnocellular neurons could directly stimulate CORT release [17] and thus participate in adaptive mechanisms of the HPA axis [3]. In addition, in our study, we observed a decreased level of BDNF mRNA, but significantly increased BDNF protein levels in the investigated brain regions of chronically stressed animals. The decreased level of BDNF mRNA after CRS could be due to the decreased stability of mRNA. Also, message degradation may be the primary target of the regulation of gene expression [18] in chronic stress conditions. In addition, the discrepancy between mRNA levels and protein levels of BDNF may be in fine control over post-transcriptional regulation of BDNF expression. A significant increase in prefrontal BDNF protein levels is an adaptive response which is probably necessary to maintain the prefrontal BDNF capacity in conditions provoked by CRS. The literature data confirm that the central administration of BDNF substantially modifies HPA axis activity [19] via direct stimulation of the CORT release [17]. An important result in our study is that we recorded a low, but significant positive correlation between the levels of BDNF in PFC and plasma levels of CORT in stress conditions. It is possible that measurements of BDNF levels in other brain areas, for example, in the hypothalamus, especially in the PVN might demonstrate a more direct relationship between levels of BDNF and CORT. The results presented in this study support the hypothesis that BDNF might be an important regulator involved in the adaptive strategy of the HPA axis to maintain adequate reactivity under chronic stimulation, which is in accordance with studies of Naert et al. [3].

\section{CONCLUSION}

Our results point to a relationship between HPA axis activity and neuronal plasticity in the PFC in stress conditions.

Acknowledgments: This work was supported by the Ministry of Education and Science of the Republic of Serbia, Contract No. III 41027, OI 173041 and III 41022 .

Conflict of interest: The authors report no conflict of interest.

\section{REFERENCES}

1. J. P. Herman et al., "Regulation of the hypothalamicpituitary-adrenocortical stress response," Compr. Physiol., vol. 6, no. 2, pp. 603 - 621, Mar. 2016.

DOI: 10.1002/cphy.c150015

PMid: 27065163

PMCid: PMC4867107

2. B.S. McEwen, "Central effects of stress hormones in health and disease: Understanding the protective and damaging effects of stress and stress mediators," Eur. $J$. Pharmacol., vol. 583, no. 2 - 3, pp. 174 - 185, Apr. 2008.

DOI: 10.1016/j.ejphar.2007.11.071

PMid: 18282566

PMCid: PMC2474765

3. G. Naert, G. Ixart, T. Maurice, L. Tapia-Arancibia, L. Givalois, "Brain-derived neurotrophic factor and hypothalamic-pituitary-adrenal axis adaptation processes in a depressive-like state induced by chronic restraint stress," Mol. Cell. Neurosci., vol. 46, no. 1, pp. 55 - 66, Jan. 2011.

DOI: 10.1016/j.mcn.2010.08.006

PMid: 20708081

4. S. Chiba et al., "Chronic restraint stress causes anxietyand depression-like behaviors, downregulates glucocorticoid receptor expression, and attenuates glutamate release induced by brain-derived neurotrophic factor in the prefrontal cortex," Prog. NeuroPsychopharmacol. Biol. Psychiatry., vol. 39, no. 1, pp. 112 - 119, Oct. 2012.

DOI: $10.1016 /$ j.pnpbp.2012.05.018

PMid: 22664354

5. J. Klein et al., "Lesion of the medial prefrontal cortex and the subthalamic nucleus selectively affect depression-like behavior in rats," Behav. Brain Res., vol. 213, no. 1, pp. 73 - 81, Nov. 2010.

DOI: 10.1016/j.bbr.2010.04.036

PMid: 20434489

6. R. M. Sullivan, A. Gratton, "Lateralized effects of medial prefrontal cortex lesions on neuroendocrine and autonomic stress responses in rats," J. Neurosci., vol. 19 , no. 7, pp. 2834 - 2840, Apr. 1999.

DOI: 10.1523/JNEUROSCI.19-07-02834.1999

PMid: 10087094 PMCid: PMC6786056

7. M. Ivković et al., "Predictive value of sICAM-1 and sVCAM-1 as biomarkers of affective temperaments in healthy young adults," J. Affect. Disord., vol. 207, pp. 47 - 52, Jan. 2017.

DOI: 10.1016/j.jad.2016.09.017

PMid: 27693464 
8. N. Popović et al., "Relationship between behaviors and catecholamine content in prefrontal cortex and hippocampus of chronically stressed rats," in Proc. 5th Int. Conf. Radiation and Applications in Various Fields of Research (RAD 2017), Budva, Montenegro, 2017, pp. 255 - 259.

DOI: $10.21175 /$ RadProc.2017.52

9. N. Popović et al., "Modulation of Hippocampal Antioxidant Defense System in Chronically Stressed Rats by Lithium," Oxid. Med. Cell. Longev., vol. 2019, Feb. 2019.

DOI: $10.1155 / 2019 / 8745376$

PMid: 30911352

PMCid: PMC6398005

10. C. Phillips, "Brain-derived neurotrophic factor, depression, and physical activity: Making the neuroplastic connection," Neural Plast., vol. 2017, Aug. 2017.

DOI: $10.1155 / 2017 / 7260130$

PMid: 28928987

PMCid: PMC5591905

11. J. S. Dunham, J. F. W. Deakin, F. Miyajima, A. Payton, C. T. Toro, "Expression of hippocampal brain-derived neurotrophic factor and its receptors in Stanley consortium brains," J. Psychiatr. Res., vol. 43, no. 14, pp. 1175 - 1184, Sep. 2009.

DOI: 10.1016/j.jpsychires.2009.03.008 PMid: 19376528

12. T. Numakawa et al., "Production of BDNF by stimulation with antidepressant-related substances," J. Biol. Med., vol. 1, no. 3, pp. 1 - 10, Jan. 2011.

Retrieved from:

https://www.researchgate.net/profile/Shuichi Chiba/pu blication/249315928 Production of BDNF by Stimula tion with Antidepressant-

related Substances/links/odeec51e4a3240a9afoooooo/ Production-of-BDNF-by-Stimulation-with-

Antidepressant-related-Substances.pdf

Retrieved on: Jan. 1, 2019

13. L. Gavrilovic, N. Spasojevic, S. Dronjak, "Subsequent stress increases gene expression of catecholamine synthetic enzymes in cardiac ventricles of chronicstressed rats," Endocrine, vol. 37, no. 3, pp. 425 - 429, Jun. 2010.

DOI: $10.1007 / \mathrm{s} 12020-010-9325-5$

PMid: 20960163
14. N. Popović et al., "Prefrontal catecholaminergic turnover and antioxidant defense system of chronically stressed rats," Folia Biol., vol. 65, no. 1, pp. 43 - 54, Apr. 2017. DOI: $10.3409 / \mathrm{fb} 65 \_1.43$

15. E. J. Whitworth, O. Kosti, D. Renshaw, J. P. Hinson, "Adrenal neuropeptides: regulation and interaction with ACTH and other adrenal regulators," Microsc. Res. Tech., vol. 61, no. 3, pp. 259 - 267, Jun. 2003.

DOI: $10.1002 /$ jemt.10335 PMid: 12768541

16. K. Pacak, M. Palkovits, I. J. Kopin, D. S. Goldstein "Stress-induced norepinephrine release in the hypothalamic paraventricular nucleus and pituitaryadrenocortical and sympathoadrenal activity: in vivo microdialysis studies," Front. Neuroendocrinol., vol. 16, no. 2, pp. 89 - 150, Apr. 1995

DOI: $10.1006 /$ frne.1995.1004

PMid: 7621982

17. E. Grazzini et al., "Vasopressin regulates adrenal functions by acting through different vasopressin receptor subtypes," Adv. Exp. Med. Biol., vol. 449, pp. 325 - 334 1998.

DOI: $10.1007 / 978-1-4615-4871-3 \_41$ PMid: 10026821

18. D. García-López et al., "Effects of strength and endurance training on antioxidant enzyme gene expression and activity in middle-aged men," Scand. J. Med. Sci. Sports, vol. 17, no. 5, pp. 595 - 604, Oct. 2007.

DOI: $10.1111 / \mathrm{j} .1600-0838.2006 .00620 . \mathrm{x}$ PMid: 17316373

19. G. Naert, G. Ixart, L. Tapia-Arancibia, L. Givalois, "Continuous i.c.v. infusion of brain-derived neurotrophic factor modifies hypothalamic-pituitary-adrenal axis activity, locomotor activity and body temperature rhythms in adult male rats," Neuroscience, vol. 139, no. 2, pp. $779-789$, May 2006.

DOI: $10.1016 /$ j.neuroscience.2005.12.028

PMid: 16457953 